\title{
Research on Countermeasures of Bilingual Teaching Based on Dual Variable Control and Least Squares Method
}

\author{
Junqiang Zhang \\ Chongqing Business Vocational College, Chongqing, China \\ zh_ang_junqiang@126.com
}

Keywords: Dual variable control; Least square method; Regression function; Normal distribution; Unbiased estimation

\begin{abstract}
Since China entered the WTO, the accounting major has gradually integrated with international, and it is imperative to strengthen the English ability of accounting major. However, higher vocational colleges are limited by the recruit students, and students' English foundation is poor. It has a lot of difficulty to directly carry on the English bilingual teaching, so the researches of bilingual teaching in higher vocational colleges have very important significance. This paper firstly investigates the students' English level of higher vocational college, and according to the investigation of the passing rate of cet 4 and cet6, it finds that the English level of higher vocational colleges is low. This paper is based on the current situation to use the double variable control theory, and this method can have statistical analysis of the proportion of Chinese and English in the process of accounting teaching. It uses the least square method to optimize the data, and finally it obtains reasonable distribution proportion of English and Chinese in the teaching process. This paper is based on the related problems of accounting major's bilingual teaching to put forward the opinion and strategy, and this can provide reliable theoretical basis for the implementation and development of bilingual teaching in higher vocational colleges.
\end{abstract}

\section{Introduction}

Since China entered the WTO, qualitative changes of the accounting environment and financial reporting environment have taken place. This can directly have influence on the changes of the whole system's research objectives, research scope and methods. The reform of accounting system must speed up the pace to adapt to the fast change. The system innovation and especially the innovation of accounting study should be in line with the international standards, and it has to strengthen the education of foreign language and the western accounting majoral thoughts[1,2]. The accounting teaching uses bilingual teaching to improve the level of English, and it also can strengthen the learning of western accounting thought. Higher vocational colleges combine the accounting majoral English with the practice, and they should improve the English level to cope with the effects of China's entry into the WTO. Therefore it puts forward the suggestions of carrying out bilingual teaching in the process of accounting teaching to actively face the challenge. It should have reliable investigation of the condition of the English level in higher vocational colleges[3].In this way, it can determine the methods of carrying out the bilingual teaching of the accounting major.

\section{Current situation of the English level of bilingual teachers and the students in higher vocational colleges}

The levels of CET3, CET4 and CET6 are the universal standards to measure the students' English level, so we should understand the present situation and level of English teaching in higher vocational colleges, and in this way we can study the passing rate of English level in the higher vocational colleges. This paper has collected achievements' statistics of CET3, CET4 and CET6 of more than 30 schools, and the results are through the statistical analysis to be drawn as the statistical table in the Table 1.

TABLE I. THE ENGLISH LEVEL OF CET3, CET4 AND CET6 IN HIGHER VOCATIONAL COLLEGES

\begin{tabular}{|c|l|l|}
\hline English level & Average scores & Passing rate \\
\hline CET3 & 421 & $86 \%$ \\
\hline CET4 & 325 & $38 \%$ \\
\hline CET6 & 310 & $5 \%$ \\
\hline
\end{tabular}




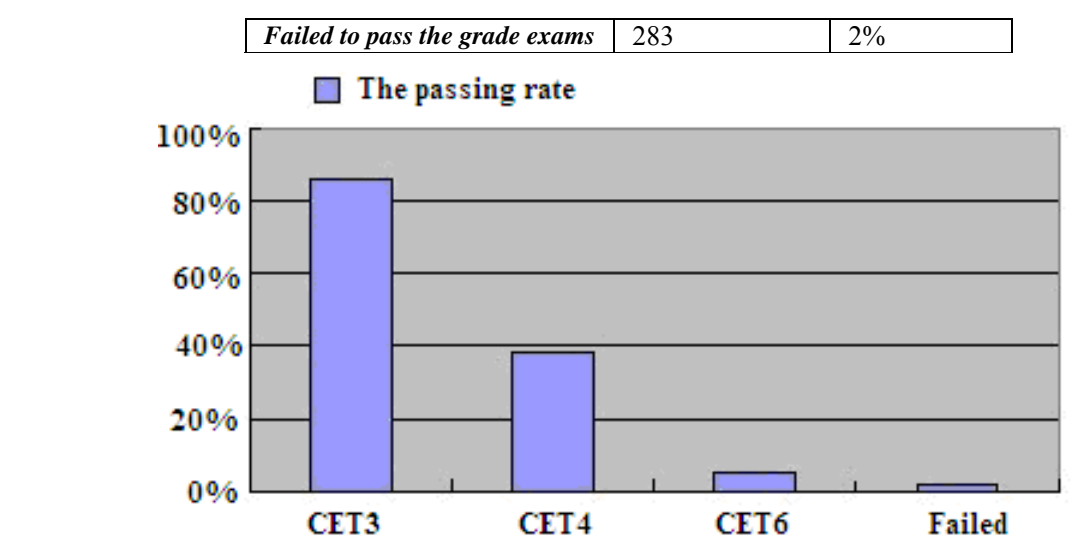

Figure 1. Diagrammatic sketch of the English level of CET3, CET4 and CET6 in higher vocational colleges

From the Table 1 and Figure 1,we can see that the passing rate of CET3 in higher vocational colleges is higher than other exams, and the passing rate of CET4 and CET6 is low. This situation reflects that the English level of most of the higher vocational colleges is still in the basic stage, and the passing rate of CET6 is low. So the bilingual teaching of higher vocational colleges must pay attention to the influencing factors of English level.

The teachers of bilingual teaching are different from the teachers of other disciplines, and the bilingual teaching requires teachers to have a basic ability in English teaching[4]. This paper has to understand the present situation of bilingual teachers in higher vocational colleges and the necessary conditions of teachers, and in this way it can have the survey of the 200 teachers and 1000 students. The final results of the investigation and statistics have statistical analysis, and they are shown in Figure 2.

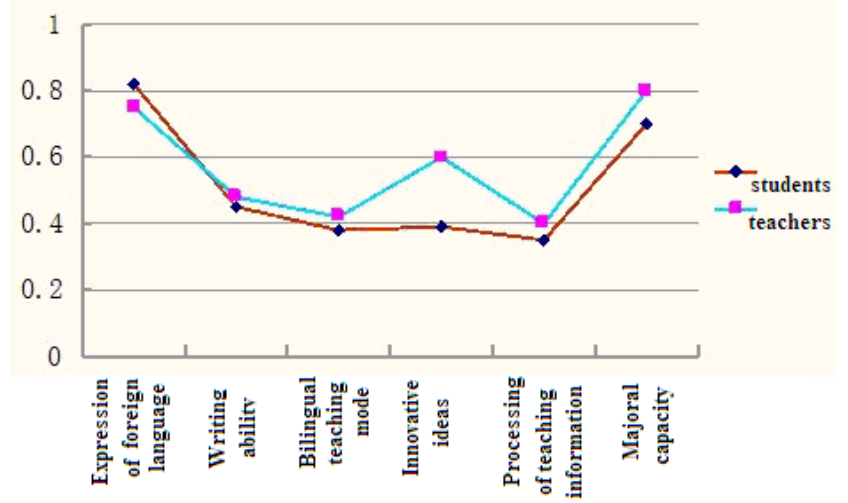

Figure 2. Survey of necessary teaching conditions of bilingual teachers

From Figure 2, it can be seen that the basic conditions of bilingual teaching are the ability of expressing foreign language and majoral ability, and most of the students voted these aspects. From the investigation it can be seen that teachers' votes of the basic condition of bilingual teaching keep balance with students' votes.

\section{Control of proportional variable of Chinese and English teaching in accounting bilingual teaching}

Firstly we introduce the double variables model, and we carry on the investigation of different proportion of Chinese and English of bilingual teaching in the five different classes, and the result is shown in Table 2.

TABLE II. INVESTIGATION OF PROPORTION OF CHINESE AND ENGLISH IN THE BILINGUAL TEACHING

\begin{tabular}{|c|l|l|l|l|l|}
\hline Size of classes & 80 & 100 & 120 & 140 & 160 \\
\hline Chinese & 50 & 55 & 72 & 78 & 93 \\
\hline English & 60 & 70 & 84 & 93 & 107 \\
\hline
\end{tabular}

The data in Table 2 respectively expresses the number of the students that support the Chinese and English, and the form gives the conditional distribution of the number of people in the condition of sizes of classes. The conditional mean is in the straight line that has positive slope. And the conditions include the general regression line (expressions regression line), the regression of the number of people to the $\mathrm{X}$ and the sizes of classes. We can see that each conditional mean $\mathrm{u}(\mathrm{Y} / \mathrm{)}$ is one of the functions of $\mathrm{A}_{i}$, and it is the linear function. 


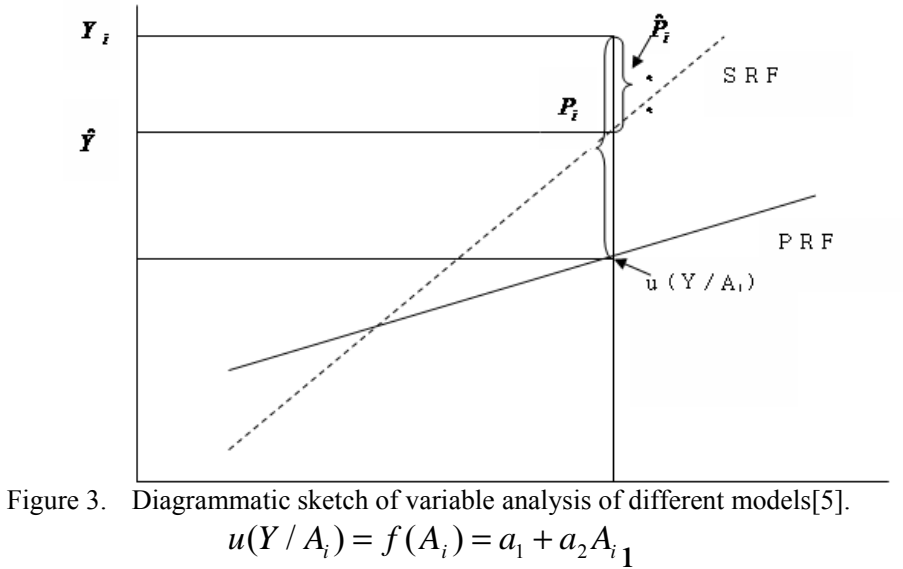

The sample regression function can be defined as[6]:

$$
\hat{Y}_{i}=\hat{a}_{1}+\hat{a}_{2} A_{i}
$$

The main purpose of regression analysis is based on the following formula.

$$
\hat{Y}_{i}=\hat{a}_{1}+\hat{a}_{2} A_{i}+P i
$$

It is through the estimation of type (3) to get the following formula.

$$
Y_{i}=\beta_{1}+\beta_{2} X_{i}+P i
$$

The least square criterion can determine the SRF to make[7]:

$$
\begin{aligned}
\sum \hat{y}_{i}^{2} & =\sum\left(Y_{i}-\hat{Y}_{i}\right)^{2} \\
& =\sum\left(Y_{i}-a_{1}-a_{2} X_{i}\right)^{2} .
\end{aligned}
$$

It uses OLS to estimate feature of the quantity in normal assumption, and $\hat{\beta}_{1}$ is the normal distribution[8-10].

$$
\begin{gathered}
E\left(\hat{a}_{1}\right)=a_{1} . . \\
\operatorname{var}\left(\hat{a}_{1}\right)=\sigma_{a_{1}}^{2}=\frac{\sum Y_{i}^{2}}{n \sum y_{i}^{2}} \sigma^{2} \\
\hat{a}_{1} \sim N\left(a_{1}, \sigma_{\hat{a}_{1}}^{2}\right) \cdot . \\
Z=\frac{\hat{a}_{1}-a_{1}}{\sigma_{\hat{a}_{1}}} .
\end{gathered}
$$

Therefore, they observe the standard normal distribution.

$\hat{a}_{2}$ obeys normal distribution[11,12].

So $Z=\frac{\hat{a}_{2}-a a_{2}}{\sigma_{\hat{a}_{2}}}$ observes the standard normal distribution.

$$
\begin{gathered}
E\left(\hat{a}_{2}\right)=\frac{a_{2} \tilde{.1}_{1}}{\sigma^{2}} \\
\operatorname{var}\left(\hat{a}_{2}\right)=\sigma_{a_{2}}^{2}=\frac{\sigma^{2}}{\sum x_{i}^{2}} .1 ! \\
\hat{a}_{2} \sim N\left(a_{2}, \sigma_{\hat{a}_{2}}^{2}\right)_{.1 .} .
\end{gathered}
$$

In the whole unbiased estimate class, the linear or nonlinear $\hat{a} 1$ and $\hat{a}_{2}$ have minimum variances and they are different from Guass- Markov theorem.

According to the statistical data of the proportion of Chinese and English in the classroom teaching, we can use the above formulas and methods to have the double variable analysis. The least squares algorithm can be used to optimize and analyze the data[13]. We also have the linear regression analysis of the normal distribution, and finally we can get the distribution proportion of Chinese and English teaching, and the results are shown in Table 3. 
TABLE III. DISTRIBUTION PROPORTION OF CHINESE AND ENGLISH AFTER THE DOUBLE VARIABLES ANALYSIS

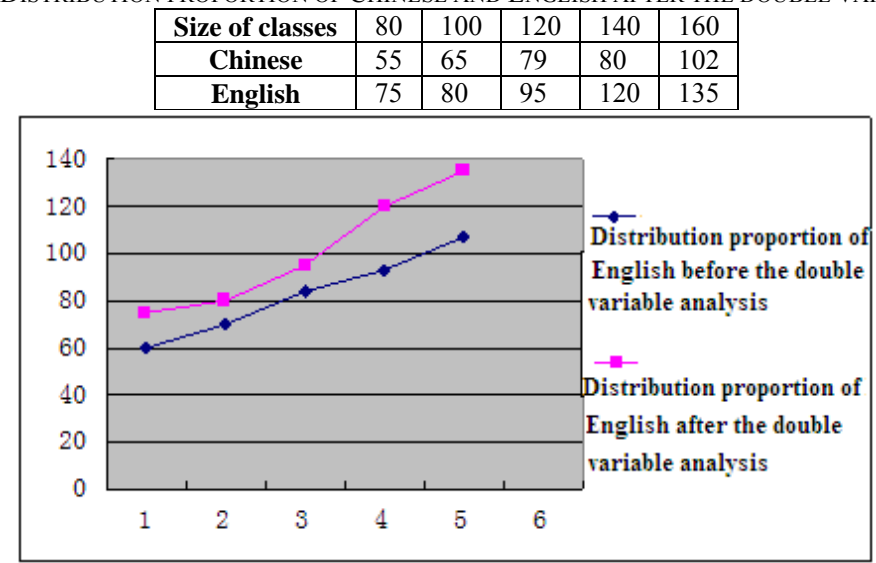

Figure 4. Contrast figure of the distribution proportion of English before and after the double variable analysis

From Table 3 and Figure 4,we can obviously see that the proportion of English of accounting bilingual teaching in higher vocational colleges is significantly increasing, and this corresponds to the goal of bilingual teaching. The bilingual teachers should strengthen the teaching of basic knowledge and skills of accounting English, and the teachers should combine the advanced accounting teaching ideas in many western countries, in this way they can obtain innovation in the class. According to the initial and normal investigation, the general students subjectively are difficult to accept the mode of bilingual teaching. But variable analysis uses the least square method and the normal distribution and other optimization methods to finally determine the objective proportion of Chinese and English in the process of bilingual teaching.

\section{Suggestions and countermeasures of bilingual teaching of accounting major in higher vocational colleges}

According to the above analysis we can see that the English level of higher vocational colleges is not high, but it uses the variable control to adjust the proportion of the usage of Chinese and English in the process of English teaching, and in this way it can obtain good performance of teaching. But there also has some deficiencies and shortcomings, so we can are put forward the following opinion[14].

(1) The usage of majoral vocabulary

Because the students' English level is not high, the teacher should use uncommon majoral vocabulary, and they can try to use the straightaway vocabulary. When uncommon words appear in the classes, the teacher should make students pay attention to the words together, and then the teachers carry on the teaching of majoral courses. At ordinary times the teachers should strengthen the students' learning of the vocabulary, and in this way the teachers can have regular tests of student's vocabulary level to understand the students' situation of mastering the majoral vocabulary, and at the same time they can control the usage of the vocabulary in the teaching process.

(2) Teaching materials and aids and teacher training

Books and multimedia are the most commonly used materials of the teachers in the classes. The teachers can use general books, and the multimedia should be more important. Multimedia has the integration of seeing and hearing, it has important influence on English teaching, so teachers should use multimedia to have bilingual teaching of accounting major. Teachers of bilingual teaching are different from teachers of other disciplines, and they should have certain majoral knowledge and the ability in the teaching of foreign language, and at the same time they have to understand the advanced western accounting ideas, only in this way they are able to do well in the teaching of higher vocational colleges.

(3) Formulation of teaching task and teaching goals

The formulation of teaching task and goals of bilingual teaching is different from that of other disciplines, bilingual teaching emphasizes ability of learning English. Therefore in the formulation of learning task and learning objectives, the teachers should make the majoral classes keep steps to the English level, and at the same they should make the suitable teaching plan and task. In the usage of teaching materials and the evaluation system of teaching methods, the teachers can draw lessons 
from modes and methods of foreign teaching, and at the same they can make the students unconsciously accept the advanced western accounting methods and concepts.

\section{Conclusion}

In the process of integrating with international, the accounting major has to deal with a large number of international accounting cases, and this will require the workers of accounting industry to have a high English level, and in this way they can be competent for the accounting industry. Higher vocational colleges have strong study and practice of accounting theory, and they should strengthen the English ability of accounting major. This paper firstly investigates the students' English level in higher vocational colleges, and it is based on the investigation of the passing rate of CET3, CET4 and CET6 to find that the English level of higher vocational colleges is lower, and the students' learning interest of English study is not high. According to this situation this paper uses the theory of dual variable control, and it is through the students' ability of accepting the knowledge and teachers' situation of using the aids to have analytic study of the proportion of Chinese and English in the process of accounting teaching. At the same time it uses the least squares theory to optimize the data, and then it obtains the reasonable distribution proportion of English and Chinese in the teaching, finally this paper puts forward some suggestions of the bilingual teaching in higher vocational colleges. Bilingual teaching is the reform of teaching, and its implementation has to shoulder heavy responsibilities. We should continue to increase the analysis of the problems in the process of bilingual teaching, and we have to carry on the immediate observation and correction of the teaching analysis, and this can make the bilingual teaching develop in the direction of the normalization. This method can let teachers really teach well, and it also can make students unconsciously accept the knowledge, finally it can realize the true meaning of bilingual teaching.

\section{References}

[1] 1. Yu Hong, Zhou Hengnan. Discussion of bilingual teaching plan of administrative accounting.Journal of .Jilin normal university (social science edition), 2010(02):36-39.

[2] 2. Li YingQi. Research of bilingual teaching practice in colleges and universities .Friend of accounting, 2011(09):17-20.

[3] 3. Chen Honglei. The practice and thought of bilingual teaching .Exploration of higher education, 2011(05):62-65.

[4] 4. Tian Cuixiang. Discussion of the implementation of accounting profession's bilingual teaching . Science and education BBS, 2010(01):28-31 .

[5] 5. Yang Zhenchang. Study on the teaching of English language.Science press, 2009:75-78.

[6] 6. Zhang Weijia. Nature, conditions and related issues of the bilingual teaching .Language teaching and research, 2012(06):49-51.

[7] 7. Richards. Longman dictionary of applied linguistics .Shanxi Province education press, 2011:37-40.

[8] 8. Li Can. Exploration of several related problems of carrying out bilingual teaching in colleges and universities - in the case of accounting discipline . Higher education research, 2011(10):5053.

[9] 9. Wu ping. Review of the bilingual teaching in the past five years . China's university teaching, 2010(05):43-45.

[10] 10. Yang Jinsong, Lei Guanghe. Consideration of constructing the learning and teaching evaluation system of bilingual courses .Journal of Shanghai university of science and technology (social sciences), 2010(06):32-35.

[11] 11. Chen Xiaohong. Look closely at the bilingual teaching in colleges and universities . The contemporary education BBS, 2011(06):85-88.

[12] 12. Fu Shuling. Analysis and thinking of the bilingual teaching .The modern university education, 2010(03):70-73.

[13] 13. Lu Jiamei, Wei Qingan, Li Qiwei. Psychology -basic theory and education practice . Shanghai: Shanghai people's publishing house, 2011:53-55.

[14] 14. Zhou Gongyun. Cognitive analysis of Krashen's input hypothesis.Journal of Jinan University ,2011(6):66-69. 